\title{
Simple Fabrication of Superhydrophobic Nickel Surface on Steel Substrate via Electrodeposition
}

\author{
Junyang Tan, Junjie Hao, Zhenqiang An, Changsheng Liu* \\ Key Laboratory for Anisotropy and Texture of Materials, Ministry of Education, Northeastern \\ University, Shenyang 110819, China \\ *E-mail: neujohnson@163.com
}

doi: $10.20964 / 2017.01 .15$

Received: 23 September 2016 / Accepted: 9 November 2016 / Published: 12 December 2016

\begin{abstract}
Preparation of artificial superhydrophobic surfaces are in urgent demand in a specific domain. In the study, we obtained superhydrophobic nickel surface on steel substrates via electrodeposition nickel process and stearic acid modification, which are facile, time-saving and eco-friendly. The surface wettability, morphologies and chemical composition were analyzed by contact angle measurement, scanning electron microscope and Fourier transform infrared spectrometry. The results indicated that the $-\mathrm{CH}_{2}-$ and $-\mathrm{CH}_{3}$ groups of low surface energy were introduced into rough surface by modification with stearic acid, the rough surface was modified from superhydrophilic to superhydrophobic. When electrodeposition current density was $60 \mathrm{~A} / \mathrm{dm}^{2}$, the as-prepared nickel surface showed excellent superhydrophobicity with a contact angle of $154.4^{\circ}$ and a sliding angle of about $2.0^{\circ}$, and possessed micro-nano rough structures. Besides, the superhydrophobic nickel surface also had a good anticorrosion performance. It is believed that the presented approach should have a prosperous future in industrial applications for the superhydrophobic surface fabrication on steel substrates.
\end{abstract}

Keywords: superhydrophobic; steel; electrodeposition; modification; anti-corrosion

\section{FULL TEXT}

(C) 2017 The Authors. Published by ESG (www.electrochemsci.org). This article is an open access article distributed under the terms and conditions of the Creative Commons Attribution license (http://creativecommons.org/licenses/by/4.0/). 